\title{
Children's perception of breathlessness in acute asthma
}

\author{
I Male, H Richter, P Seddon
}

\begin{abstract}
Aim-To determine whether asthmatic children who present to hospital with hypoxia perceive breathlessness less well than non-hypoxic presenters.

Methods-A total of 27 children aged 5-16 years (mean age 10) admitted with acute asthma had recordings of oxygen saturation $\left(\mathrm{SaO}_{2}\right)$, clinical score, forced expiratory volume in one second $\left(\mathrm{FEV}_{1}\right)$, and breathlessness score (HMP) at admission and at 5, 10, 24, 48, and 72 hours after admission. Those defined as hypoxic $\left(\mathrm{SaO}_{2}\right.$ $<92 \%$ ) at admission were compared with a non-hypoxic group.

Results-Twelve children were hypoxic at admission. Compared with the nonhypoxic group they were younger (8.6 (SD 2.8) $v 11.2(2.8) \mathrm{y}, \mathrm{p}=0.02)$, and had greater airway obstruction $\left(\mathrm{FEV}_{1} 32.5\right.$ (10)\% $v 54.3$ $(26) \%, p=0.0073,95 \%$ confidence interval (CI) -36.9 to -6.6 ) yet had a trend towards less breathlessness (median HMP $4 v 3$, $p=0.062, C I-0.001$ to 2.00 ) at admission. The hypoxic group had a smaller change in breathlessness from admission to discharge, despite a similar improvement in $\mathrm{FEV}_{1}$, reflected in a lower ratio of change in HMP to change in $\mathrm{FEV}_{1}\left(\Delta \mathrm{HMP} / \Delta \mathrm{FEV} \mathrm{V}_{1}\right)$ (median $\triangle H M P / \Delta F E V_{1} 0.021 \%^{-1} v 0.073 \%^{-1}$, $\mathrm{p}=0.0081$, CI -0.075 to -0.016$)$. Linear regression analysis showed a strong relation between $\triangle H M P / \Delta F E V_{1}$ and initial $\mathrm{SaO}_{2}$ $(\mathrm{p}=0.004, r=0.54)$.

Conclusions-Asthmatic children who present to hospital hypoxic tend to perceive themselves as less breathless than non-hypoxic children. This may predispose to a future life threatening attack. (Arch Dis Child 2000;83:325-329)
\end{abstract}

Keywords: asthma; perception of breathlessness

Despite many advances in its management, childhood asthma mortality rates, in the United Kingdom, remain static at approximately 0.5 per 100000 per year. ${ }^{1-3}$ Research into the causes of asthma deaths falls into two main categories: retrospective case reviews of actual deaths; and studies of subjects with a previous life threatening attack, who are known to have a high risk of subsequently dying from asthma. ${ }^{4-8}$

In children, deaths occur at two peak age groups: preschool children, ${ }^{39}$ and teenagers. ${ }^{369}$ In the former they occur mostly in hospital, reflecting the difficulties in treating young children. In teenagers, as with adults, many deaths occur at home or on the way to hospital. ${ }^{236}$ While this sometimes reflects the rapidity of onset, $^{38}$ fatal attacks frequently develop over several hours. ${ }^{3}{ }^{10}$ On review the latter have often been rated as avoidable, ${ }^{410}$ for in this age group, once effective treatment is started it is unusual for death to occur. ${ }^{10}{ }^{11}$ Martin et al, in reviewing the circumstances of life threatening attacks in 30 children, found $80 \%$ had gradual onset, $17 \%$ sudden onset, and judged $83 \%$ as preventable. ${ }^{10}$ The commonest reason identified for preventable asthma deaths has been delay in seeking medical care..$^{4-610-12}$

Recent research in adults, largely based on patients with a previous life threatening attack, has suggested that many such patients have a reduced ability to recognise the deterioration in their asthma, through a decreased ability to perceive the sensation of breathlessness. ${ }^{4} 1314$ McFadden suggests: "Some patients are unable to sense the presence of even marked airway obstruction and have no symptoms until their respiratory reserve is virtually exhausted. Thus when they report breathlessness and wheezing, they may be close to death". ${ }^{5}$

As yet there is little research into perception of breathlessness in children. The aim of this study was to determine whether poor perception of breathlessness could be a factor in children presenting to hospital with a severe attack. We used the presence of significant hypoxia (oxygen saturation $\left.\left(\mathrm{SaO}_{2}\right)<92 \%\right)$ at admission as an indicator of a severe, and potentially life threatening, asthma attack. Geelhoed et al have shown that an initial $\mathrm{SaO}_{2}<92 \%$ at hospital admission predicts a severe attack, likely, for example, to require intravenous therapy. ${ }^{15}$ Our hypothesis was that children with poor perception of breathlessness are more likely to present to hospital having already developed significant hypoxia.

\section{Methods}

Children (aged 5-16 years) admitted to the Royal Alexandra Children's Hospital in Brighton from September to December 1995 were entered into the study and assessed on repeated occasions: soon after admission ( 0 hours), and then at 5, 10, 24, 48, and 72 hours or until discharge. An initial history recorded details of age, sex, length of acute illness, including any delays in presentation, previous need for intensive care or intravenous therapy, source of referral, severity of chronic symptoms, and acute and chronic treatment. A score was given for severity of chronic symptoms and level of chronic treatment, based respectively on the Global Initiative for Asthma (GINA) ${ }^{1}$ and the 1997 British Thoracic Society (BTS) asthma guidelines for adults and schoolchildren. ${ }^{16}$ The chronic symptom score allocated was 1 for GINA stage "intermittent" up to 4 for GINA stage "severe persistent". The treatment score allocated was equivalent 
Table 1 Characteristics of the total, hypoxic, and non-hypoxic study groups

\begin{tabular}{lllll}
\hline Characteristic & Total & Hypoxic & Non-hypoxic & Significance \\
\hline Age (y) & $10.0(\mathrm{SD} 3.0)$ & $8.6(\mathrm{SD} 2.8)$ & $11.2(\mathrm{SD} 2.8)$ & $\mathrm{p}=0.02$ \\
Median $\Delta \mathrm{HMP} / \Delta \mathrm{FEV}_{1}\left(\%^{-1}\right)$ & 0.042 & 0.021 & 0.073 & $\mathrm{p}=0.0081$ \\
Male sex & $16 / 27$ & $8 / 12$ & $8 / 15$ & $\mathrm{p}=0.48$ \\
Length acute illness (h) & $62(101)$ & $45(44)$ & $76(130)$ & $\mathrm{p}=0.45$ \\
Median chronic treatment score & $2(1-4)$ & $2(1-3)$ & $2(1-4)$ & $\mathrm{p}=0.27$ \\
Median chronic severity score & $2(1-4)$ & $2(1-4)$ & $3(1-4)$ & $\mathrm{p}=0.71$ \\
Self referral rate & $21 / 27$ & $9 / 12$ & $12 / 15$ & $\mathrm{p}=0.76$ \\
Previous ICU/IV therapy & $2 / 26$ & $2 / 11$ & $0 / 15$ & $\mathrm{NS}$ \\
\hline
\end{tabular}

to the number of the BTS Asthma Guidelines treatment step.

On each occasion the child was first asked to score how breathless they felt using the "How Much Puff" (HMP) scale. This computerised scale used the concept of blowing up a balloon to represent the degree of breathlessness felt, asking the question "How much puff have you got?" This gives a six point scale, with a small balloon (score 1) representing little puff, or maximal breathlessness, and a large balloon (score 6) representing lots of puff, or minimal breathlessness. This had been previously validated in a group of 15 children with mild asthma. ${ }^{17}$ Each child was asked to record HMP scores during a histamine challenge and while breathing through different external airway resistances (EARs). The children were able to report significant changes in perceived breathlessness in response to relatively small changes in airway obstruction. During the histamine challenge, a $20 \%$ drop in $\mathrm{FEV}_{1}$ produced a fall in HMP score from 5.6 (SD 0.6) to $3.9(0.9)$, $\mathrm{p}<0.0001$. Changing EAR from 5 to 10 $\mathrm{cm} / \mathrm{H}_{2} \mathrm{O} / 1 / \mathrm{s}$ reduced median HMP score from 6 to $5(\mathrm{p}=0.012)$. To assess repeatability the

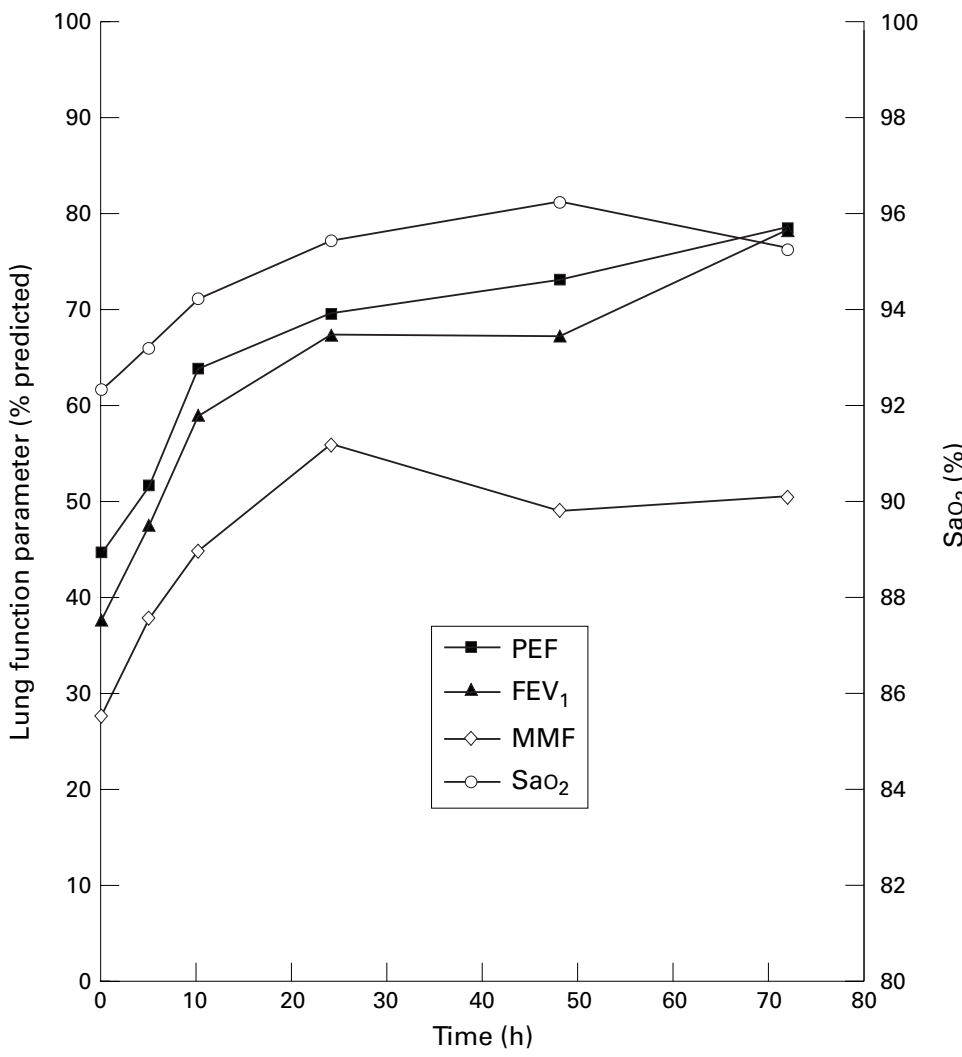

Figure 1 Changes in lung function parameters (\% predicted) and $\mathrm{SaO}_{2}(\%)$ during admission, for the total study group. external resistance studies were repeated two weeks later. Mean differences (MD) between visits and coefficients of repeatability $(\mathrm{COR})^{18}$ were small: for example at $5 \mathrm{cmH}_{2} \mathrm{O} / \mathrm{l} / \mathrm{s}, \mathrm{MD}$ was -0.29 , COR 0.61. These results suggested that HMP could be used to measure breathlessness, and compared favourably with the two adult scales (Borg scale and a visual analogue scale $)^{19}$ tested simultaneously. The latter scale has been used previously in children. ${ }^{20} 21$

Clinical score as developed and validated by Wood and colleagues ${ }^{22}$ was then assessed. With this a maximum score of 10 is obtainable, representing clinical signs of severe asthma. $\mathrm{SaO}_{2}$ was then recorded by pulse oximetry (Biox 3700e pulse oximeter, Ohmeda, Louisville, USA). At the same time, spirometry, including peak expiratory flow (PEF), forced expiratory volume in one second $\left(\mathrm{FEV}_{1}\right)$, and maximal mid expiratory flow (MMF) - a measure of small airway function-was recorded using a pneumotachograph spirometer (Master Screen Pneumo 4.2, Erich Jaeger, Wurzburg, Germany), and expressed in all cases as percent predicted for height.

Mean values for each of the observations were calculated for the total study group at admission (0 hours), and at 5, 10, 24, 48, and 72 hours after admission, and plotted graphically. Initial HMP score, $\mathrm{FEV}_{1}$, and the ratio of initial HMP to initial $\mathrm{FEV}_{1}$, for the hypoxic and non-hypoxic groups were compared using the MannWhitney $\mathrm{U}$ test. The relation between the ratio of initial HMP to initial $\mathrm{FEV}_{1}$ and initial $\mathrm{SaO}_{2}$, was also assessed, using linear regression.

The ratio of change in HMP score to the change in $\mathrm{FEV}_{1}$ between first and last assessments $\left(\triangle \mathrm{HMP} / \Delta \mathrm{FEV}_{1}\right)$ was then calculated to assess the individual subject's ability to perceive changes in airway obstruction. The change was that between the first assessment (0 hours) and the final assessment before discharge: mean interval (SD) 32 hours (21.5). Multiple regression analysis was used to examine the possible relation between $\Delta \mathrm{HMP} /$ $\Delta \mathrm{FEV}_{1}$ and $\mathrm{SaO}_{2}$, and additionally age, length of acute illness, chronic asthma score, and chronic treatment level. The Mann-Whitney $\mathrm{U}$ test was used to compare $\Delta \mathrm{HMP} / \Delta \mathrm{FEV}_{1}$ in the hypoxic and non-hypoxic groups. These were further compared with the results of 14 children (mean age 10.5 years) with mild asthma in whom the $\Delta \mathrm{FEV}_{1}$ was induced by a histamine challenge as part of the previous study validating the breathlessness scale (mild asthma group).

Ethical approval was obtained from the Brighton Area Ethics Committee. Signed, informed consent was obtained from parents and, when appropriate, the child.

\section{Results}

A total of 27 children were recruited with mean age 10 years. Of these 12 had significant hypoxia $\left(\mathrm{SaO}_{2}<92 \%\right)$ at admission. The hypoxic group were younger (8.6 (SD 2.8) years) $v 11.2(2.8)$ years, $\mathrm{p}=0.02)$, but otherwise both groups were similar (see table 1 ).

Mean values for larger airway obstruction, as indicated by $\mathrm{PEF}$ and $\mathrm{FEV}_{1}$, improved rapidly in the first 10 hours after admission (see fig 1) 


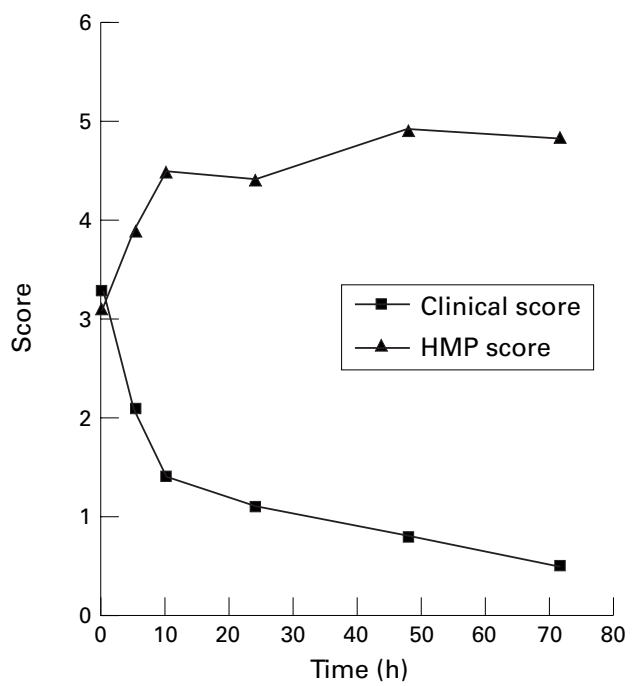

Figure 2 Changes in HMP score and clinical score during admission, for the total study group.

but more slowly thereafter. Clinical score showed a similar pattern of improvement (see fig 2). Small airway obstruction, reflected by $\mathrm{MMF}$, was slow to improve, reached a plateau, and was still below $50 \%$ predicted at 72 hours. $\mathrm{SaO}_{2}$, which in part also reflects small airway function, was similarly slow to improve. It is notable that improvement in perceived breathlessness (increasing HMP score in fig 2) mirrors the pattern of large airway parameters, continuing to improve between 20 and 72 hours, when $\mathrm{MMF}$ and $\mathrm{SaO}_{2}$ were static.

Comparison of the hypoxic and non-hypoxic groups at admission showed, as one would expect, significantly worse lung function in the hypoxic group (mean $\mathrm{FEV}_{1}$, as percent predicted, 32.5 (SD 10)\% v 54.3 (26)\%, $\mathrm{p}=0.0073$, CI -36.9 to -6.6$)$. Despite this, there was a trend for the initially hypoxic children to report less initial breathlessness (median HMP $4 v 3, \mathrm{p}=0.062, \mathrm{CI}-0.001$ to 2.00 , see fig 3). The $\mathrm{HMP} / \mathrm{FEV}_{1}$ ratio was higher in the hypoxic group (median $0.126 \%^{-1} v$ $\left.0.051 \%^{-1}, \mathrm{p}=0.0025\right)$ and negatively related to initial $\mathrm{SaO}_{2}(r=0.50, \mathrm{p}=0.008)$. This might suggest that the greater the degree of hypoxia at admission, the less breathlessness (that is, a relatively higher HMP score) the

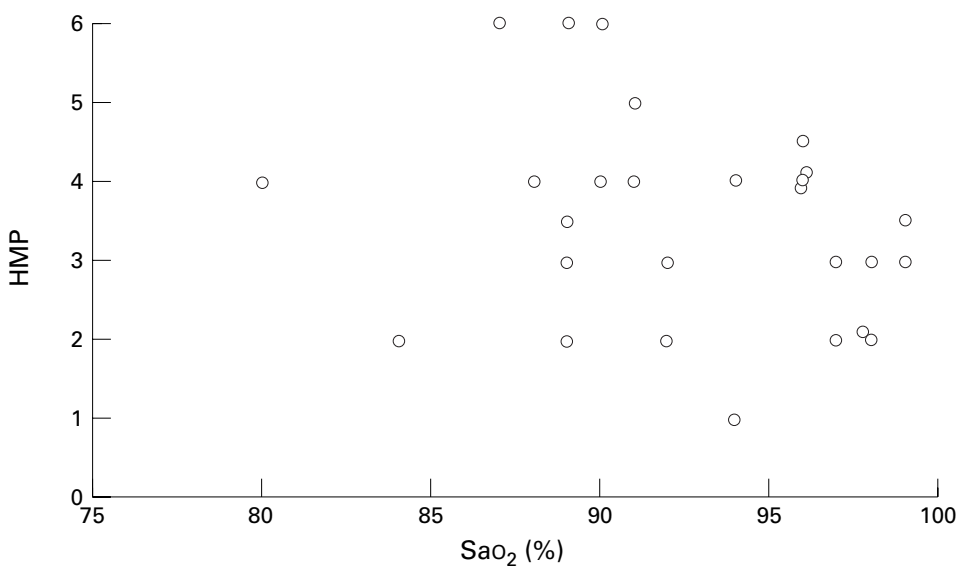

Figure 3 Initial HMP score plotted against initial $\mathrm{SaO}_{2}(\%)$. child reported, relative to the degree of airway obstruction. However it is also possible that this relation might simply reflect the expected relation between $\mathrm{SaO}_{2}$ and $\mathrm{FEV}_{1}$ : hypoxic children tending to have lower $\mathrm{FEV}_{1}$ and hence a higher $\mathrm{HMP} / \mathrm{FEV}_{1}$ ratio.

We therefore went on to examine the ratio of changes in breathlessness score and airway obstruction: $\triangle \mathrm{HMP} / \triangle \mathrm{FEV}_{1}$. The higher this ratio, the greater is the change in breathlessness felt for a given change in lung function; in other words the more aware the subject is of the change in severity of his asthma. $\triangle \mathrm{FEV}_{1}$ was similar in the hypoxic and non-hypoxic groups (mean 35 (19) v 32 (17), p=0.66), but the hypoxic children had a significantly lower $\Delta \mathrm{HMP} / \Delta \mathrm{FEV}_{1}$ (median $0.021 \%^{-1} v 0.073 \%^{-1}$, $\mathrm{p}=0.0081$, CI -0.075 to -0.016 , see fig 4 ), suggesting that they were less aware of changes in airflow obstruction. The hypoxic group also had a significantly lower $\Delta \mathrm{HMP} / \Delta \mathrm{FEV}_{1}$ than the mild asthma group (median $0.021 \%^{-1} v$ $0.097 \%^{-1}, \mathrm{p}=0.0001$, CI -0.11 to -0.042 ) while the non-hypoxic and mild asthma groups were similar $(\mathrm{p}=0.12)$.

Linear regression analysis showed a significant, positive relation between $\Delta \mathrm{HMP} / \Delta \mathrm{FEV}_{1}$ and initial $\mathrm{SaO}_{2}(r=0.54, \mathrm{p}=0.004$, see fig 5). This relation persisted $(\mathrm{p}=0.011)$ on performing multiple linear regression analysis, although no relation could be shown with age $(p=0.15)$, chronicity score $(p=0.65)$, length

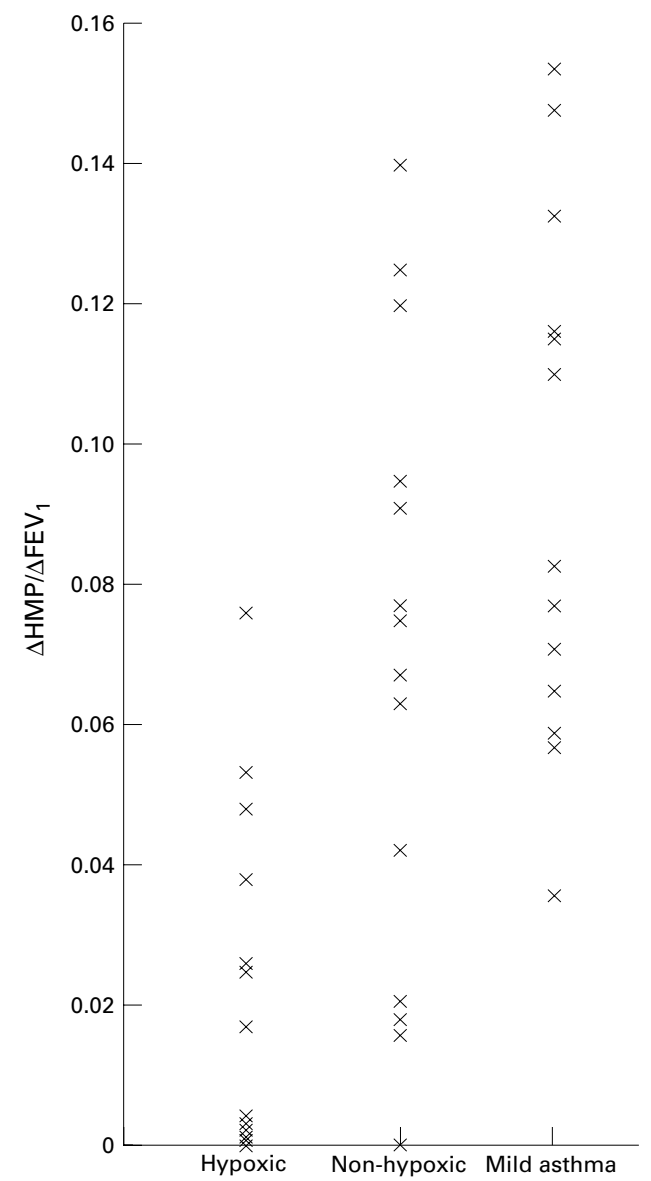

Figure $4 \triangle H M P / \triangle F E V_{1}\left(\%^{-1}\right)$ ratios for the hypoxic, non-hypoxic, and mild asthmatic (validation) groups. Individual values and median are shown. 


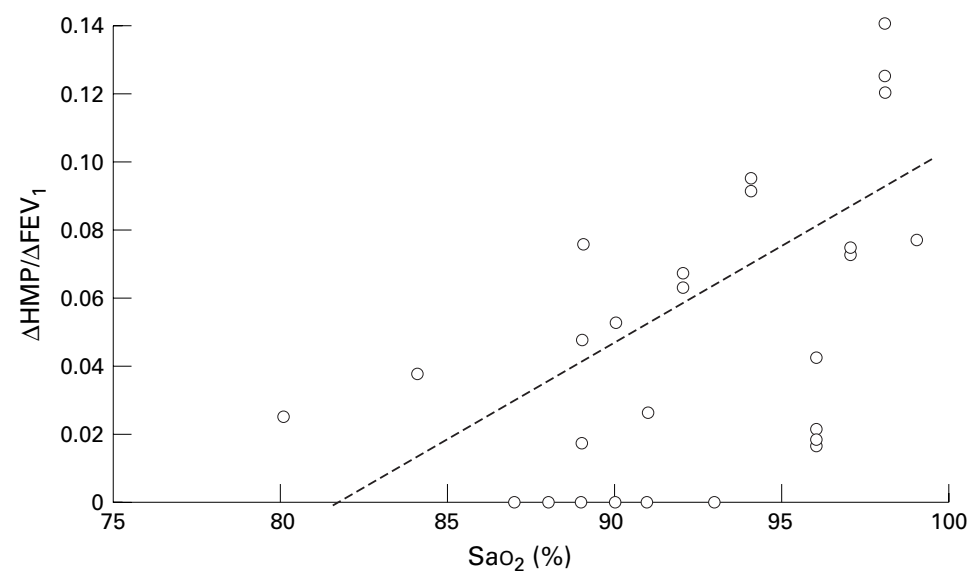

Figure $5 \triangle H M P / \triangle F E V_{1}\left(\%^{-1}\right)$ ratio plotted against initial SaO for the total study group. The regression line is shown.

of illness $(p=0.37)$, or level of chronic treatment $(\mathrm{p}=0.37)$.

\section{Discussion}

This study showed that, overall, children were able to recognise and report decreasing breathlessness as measures of larger airway function improved. This suggests that the HMP scale enables children to report breathlessness appropriately. Changes in clinical score followed a similar pattern. Small airway obstruction, measured by $\mathrm{MMF}$ and reflected by $\mathrm{SaO}_{2}$, persisted even as the child appeared to be, and felt, better, as has previously been recognised both following an acute attack ${ }^{23}$ and in asymptomatic asthmatics. ${ }^{24-26}$

However, those children who were hypoxic at presentation to hospital, appeared to have reduced perception of breathlessness. They had a trend towards reporting lower initial levels of breathlessness despite significantly greater airway obstruction, and experienced a smaller decrease in breathlessness felt for a similar improvement in $\mathrm{FEV}_{1}$, in comparison with children presenting without hypoxia and with mild asthmatics not admitted to hospital. This observation is supported by the direct relation between ability to perceive breathlessness and initial $\mathrm{SaO}_{2}$, such that the greater the degree of initial hypoxia, the less able the child was to perceive breathlessness. This is also consistent with studies in adults showing that those presenting with life threatening asthma attacks perceive breathlessness poorly, ${ }^{451314}$ and has been reported in two children who died from acute asthma. ${ }^{27}$ Our results suggest that poor perception may be one of the factors which causes children to present to hospital with advanced, potentially life threatening, acute asthma.

It could be argued that poor perception in the hypoxic group resulted from their being slightly younger; however we could show no relation between age and ability to perceive breathlessness. An alternative explanation for our findings is that perception of breathlessness may be influenced by the presence of hypoxia. However, poor perception of breathlessness persisted even as $\mathrm{SaO}_{2}$ returned to normal. Furthermore, the evidence in adults suggests that poor perception of breathlessness is present before and after the attack, in the absence of hypoxia. ${ }^{13}$ It would seem more likely that the patient with poor perception fails to recognise the severity of the deterioration in his asthma, and therefore delays seeking help, ${ }^{4} 13$ such that markers of acutely severe asthma, such as hypoxia, are likely to be present on arrival at hospital. It has also been observed that adults with a previous near fatal attack and poor perception of breathlessness may have a greatly reduced hypoxic ventilatory response, predisposing them to develop hypoxia during an acute attack. ${ }^{13}$

Our findings provide evidence in support of the hypothesis that differences in perception of breathlessness occur among asthmatic children, and influence the severity of presentation to hospital. If this is true, where could these differences in perception arise from? They may simply be caused by a normal distribution of perception of breathlessness. ${ }^{28}$ There is evidence for a genetic influence, for example in family studies of asthmatics with a history of respiratory failure, ${ }^{29-31}$ or in natives of high altitude regions ${ }^{32} 33$ and endurance sportsmen ${ }^{34} 35$ where this may confer an evolutionary advantage. However, other studies suggest poor perception of breathlessness develops as an adaptive characteristic, for example on moving to, ${ }^{32}$ or training at high altitude, ${ }^{36}$ or in chronic cardiopulmonary disease, such as chronic persistent asthma ${ }^{37}$ or congenital cyanotic heart disease. ${ }^{38}{ }^{39}$ Medical intervention, such as carotid body resection, ${ }^{40}$ may also have an influence. If poor perception is acquired it could also be possible to reverse it, for example by aggressive management of chronic airway obstruction.

In summary, this study suggests that reduced perception of airway obstruction and breathlessness may be associated with hypoxic presentation to hospital during acute asthma. As research in adults suggests poor perceivers of breathlessness are at risk of dying from a future asthma attack, then presence of significant hypoxia at admission should be taken as a warning of future severe attacks, which the child may not be able to recognise. It is therefore important to measure $\mathrm{SaO}_{2}$ at admission, and in those children found to be initially hypoxic, to consider regular objective measurement of airflow obstruction, for they may not otherwise be able to recognise when their asthma is deteriorating. While home peak flow measurement or spirometry may help, further research is required to determine how best to monitor such children and prevent future life threatening attacks.

1 Global strategy for asthma management and prevention. NHBLI/WHO workshop report. Global initiative for asthma. Bethesda: National Institutes of Health, 1995.

2 Carswell F. Thirty deaths from asthma. Arch Dis Child 1985;60:25-8.

3 Fletcher H, Ibrahim S, Speight N. Survey of asthma deaths in the Northern region. Arch Dis Child 1990;65:163-7.

4 Barnes P. Blunted perception and death from asthma. N Engl $\mathcal{F}$ Med 1994;330:1383-4.

$5 \mathrm{McF}$ adden E. Fatal and near fatal asthma. $N$ Engl $f \mathrm{Med}$ 1991;324:409-11.

6 Robertson C, Rubinfield A, Bowes G. Pediatric asthma deaths in Victoria: the mild are at risk. Pediatr Pulmonol 1992;13:95-100. 
7 Newcomb R, Akhter J. Respiratory failure from asthma-a marker for children with high morbidity and mortality. $A n$ 7 Dis Child 1988;142:1041-4.

8 Kravis L, Kolski G. Unexpected death in childhood asthma. Am $\mathcal{F}$ Dis Child 1985;139:558-63.

9 Seddon P, Heaf D. Long term outcome of ventilated asthmatics. Arch Dis Child 1990;65:1324-8.

10 Martin A, Campbell D, Gluyas P, et al. Characteristics of near-fatal asthma in childhood. Pediatr Pulmonol 1995;20 $1-8$.

11 Sears $M$, Rea $H$. Patients at risk for dying of asthma: New Zealand experience. F Allergy Clin Immunol 1987;80:47781

12 Simons F, Pierson W, Bierman C. Respiratory failure in childhood status asthmaticus. Am f Dis Child 1977;131: 1097-101.

13 Kikuchi Y, Okabe S, Tamura G, et al. Chemosensitivity and perception of dyspnea in patients with a history of near
fatal asthma. NEngl $\mathcal{H}$ Med 1994;330:1329-34.

14 Ruffin R, Latimer K, Schembri D. Longitudinal study of near fatal asthma. Chest 1991;99:77-83.

15 Geelhoed G, Landau L, Le Souef P. Predictive value of oxygen saturation in emergency evaluation of asthmatic gen saturation in emergency

16 The British Guidelines on Asthma Management. Thorax 1997;52(suppl 1): S1-24.

17 Male I, Seddon P. The measurement of breathlessness in children with asthma. Am f Resp Crit Care Med 1996;153 A557.

18 Bland J, Altman D. Statistical methods for assessing agreement between two methods of clinical measurement. Lancet 1986;i:307-10.

19 Wilson R, Jones P. A comparison of the visual analogue scale and modified Borg scale for the measurement of dyspnoea during exercise. Clin Sci 1989;76:277-82.

20 Fritz G, Klein R, Overholser J. Accuracy of symptom perception in childhood asthma. F Dev Behav Pediatr 1990; perception

21 Rietveld S. Habituation to prolonged airflow obstruction. F Asthma 1997;34:133-9.

22 Wood D, Downes J, Lecks H. A clinical scoring system for the diagnosis of respiratory failure. Am $\mathcal{f}$ Dis Child the diagnosis of

23 Mihatsch W, Geelhoed G, Landau L, Le Souef P. Time course of change in oxygen saturation and peak expiratory flow rate in children admitted to hospital with acute asthma. Thorax 1990;45:438-41.

24 Ferguson A. Persisting airway obstruction in asymptomatic children with asthma with normal peak expiratory flow rates. F Allergy Clin Immunol 1988; 82:19-22.
25 Canny G, Levison H. Pulmonary function abnormalities during apparent clinical remission in childhood asthma. during apparent clinical remission

26 Hill D, Landau L, Mcnicol K, Phelan P. Asthma-the physiological and clinical spectrum in childhood. Arch Dis Child 1972;47:874-81

27 Zach M, Karner U. Sudden death in asthma. Arch Dis Child 1989;64:1446-51.

28 Boulet L-P, Leblanc P, Turcotte H. Perception scoring of induced bronchoconstriction as an index of awareness of asthma symptoms. Chest 1994;105:1430-3.

29 Hudgel D, Weil J. Asthma associated with decreased hypoxic ventilatory drive, a family study. Ann Int Med 1974;80: $622-5$.

30 Hutchison A, Olinsky A. Hypoxic and hypercapnic response in asthmatic subjects with previous respiratory failure. Thorax 1981;36:759-63.

31 Moore G, Zwillich C, Battaglia J, Cotton E, Weil J. Respiratory failure associated with familial depression of ventilatory response to hypoxia and hypercapnia. $N$ Engl $\mathcal{F} \mathrm{Med}$ 1976;295:861-5.

32 Weil J, Byrne-Quinn E, Sodal I, Filley G, Grover R. Acquired attenuation of chemoreceptor function in chronically hypoxic man at high altitude. F Clin Invest 1971:50: 186-95.

33 Beral V, Read DJC. Insensitivity of respiratory centre to carbon dioxide in the Enga people of New Guinea. Lancet 1971;ii:1290-4.

34 Scoggin C, Doekel R, Kryger M, et al. Familial aspects of decreased hypoxic drive in endurance athletes. $\mathcal{F} \mathrm{Appl}$ Physiol 1978;44:464-8.

35 Saunders N, Leeder S, Rebuck A. Ventilatory response to carbon dioxide in young athletes: a family study. Am Rev Resp Dis 1976;113:497-502.

36 Wilson R, Oldfield L, Jones P. Effect of residence at altitude on the perception of breathlessness on return to sea level in normal subjects. Clin Sci 1993;84:159-67.

37 Orehek J, Beaupre A, Badier M, et al. Perception of airway tone by asthmatic patients. Bull Eur Physiopathol Respir 1982;18:601-7.

38 Sorensen C, Severinghaus J. Respiratory insensitivity to acute hypoxia persisting after correction of tetralogy of Fallot. F Appl Physiol 1968;25:221-3.

39 Edelman N, Lahiri S, Braudo L, et al. The blunted ventilatory response to hypoxia in cyanotic congenital heart disease. N Engl f Med 1970;282:405-11.

40 Chang K, Morrill C, Chai H. Impaired response to hypoxia after bilateral carotid body resection for treatment of bronchial asthma. Chest 1978;73:667-9. 